\title{
USING ADAPTIVE DESIGNS TO PROMOTE SOCIAL INTERACTION IN AN INCLUSIVE EARLY LEARNING ENVIRONMENT: ONE CHILD'S STORY
}

By

\author{
Alison Gaston \\ A Major Research Paper \\ presented to Ryerson University \\ in partial fulfillment of the \\ requirements for the degree of \\ Master of Arts \\ in the program of \\ Early Childhood Studies
}

Bachelor of Arts, Early Childhood Education, Ryerson University, 2009

Toronto, Ontario, Canada, 2011

(C) Alison Gaston 2011 


\section{Author's Declaration}

I hereby declare that I am the sole author of this major research paper.

I authorize Ryerson University to lend this major research paper to other institutions or individuals for the purpose of scholarly research.

$\overline{\text { Signature }}$

I further authorize Ryerson University to reproduce this major research paper by photocopying or by other means, in total or in part, at the request of other institutions or individuals for the purpose of scholarly research.

$\overline{\text { Signature }}$ 
USING ADAPTIVE DESIGNS TO PROMOTE SOCIAL INTERACTION IN AN INCLUSIVE

EARLY LEARNING ENVIRONMENT: ONE CHILD’S STORY

\author{
(C) Alison Gaston 2011 \\ Masters of Arts \\ Early Childhood Studies \\ Ryerson University
}

\begin{abstract}
This qualitative research study employs narrative inquiry methods to both tell and explore the story of Zivvie (a pseudonym), a preschool child with severe disabilities, and her journey in becoming a full member of her learning community in an inclusive setting. The inquiry examines the changes in her social interactions with her peers resulting from the introduction of custom adaptive design objects, and how the use of adaptive designs provided Zivvie with a level of autonomy that enabled her to make choices about how she wanted to participate in her learning community. The inquiry also explores how the teacher's role as observer and creator of accommodations for Zivvie within the learning environment facilitated the child's development. Recommendations for future practice and research are identified.
\end{abstract}

Key Words: 'preschool child', ‘inclusion', ‘social interactions', ‘early learning environments', ‘adaptive designs’, ‘accommodations’ 


\section{Acknowledgements}

Jason Nolan: Thank you for your support throughout this process. You have made me continue to question, reflect, investigate, create and be inspired by all that is being constructed around me. Angela Valeo: Thank you for your inspiration to look at the child beyond the assessments. Judith Bernhard \& Rachel Langford: Thank you for your support and encouragement as I navigated the realm of graduate studies.

Roxie MacPherson: For being my 'best friend', for more years then either of us wants to remember, you were there to provide the loving support needed to get me through the tough times, the lonely times, the happy times by just being you, my friend.

Brenda Nolan: For always being willing to reschedule when I couldn't be there and provide the support of a true friend, providing the tissues when I cried and the words that allowed me to carry on.

My work colleagues: For your daily inspiration, you helped me understand what it means to be an ECE working in an early learning environment that believes in inclusion.

My school colleagues: For challenging my 'habits of mind', to question the answers and to never forget that we can always learn.

The research participants: This story would not have been told without your contributions, you were all an inspiration on how inclusion can be successful. Especially Zivvie, your story continues to inspire me to be a better educator. 


\section{Dedication}

To my wonderful family, John, Lisa, Thomas, James, Tara and the lovely Claire your love and support daily allows me to believe that anything is possible.

To Terri, my sister, you always pushed me to believe in me. To live, love and laugh. 


\section{Table of Contents}

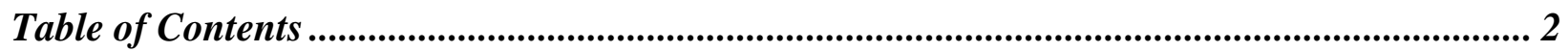

Chapter 1: Introduction, "Zivvie is my best friend" ....................................................... 4

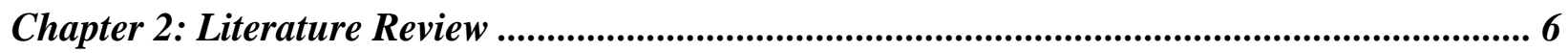

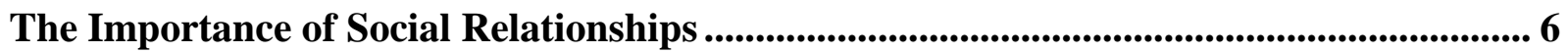

Current Research on Social Interactions in Inclusive Environments.............................. 10

Parents' Attitudes and Beliefs on the Benefits of Inclusive Settings................................... 10

Social Interactions and Friendship Development ............................................................. 12

Current Research on Strategies to Promote Social Interactions.......................................... 14

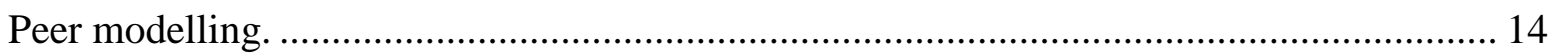

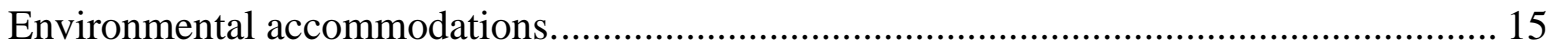

Adaptive Design ................................................................................................................................ 16

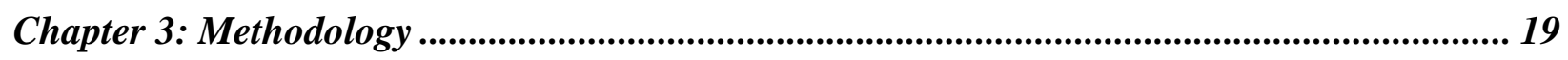

Strategy

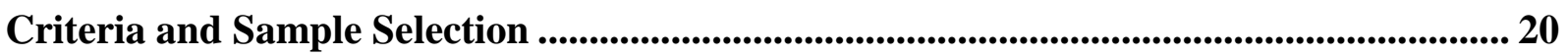

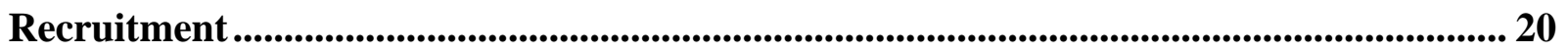

Participants......................................................................................................................................... 21

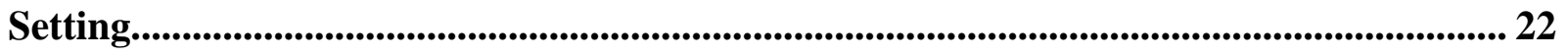

Data collections tools........................................................................................................................ 23

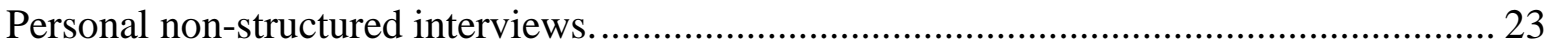


Written responses.

Observations.

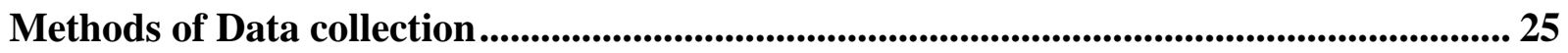

Data Organization................................................................................................................................ 25

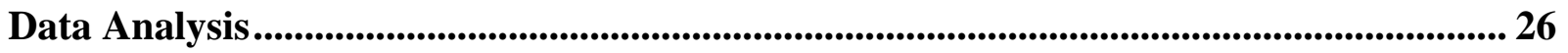

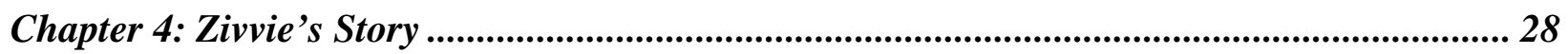

Chapter 5: Discussion................................................................................................... 42

Chapter 6: Conclusion and Recommendation............................................................... 54

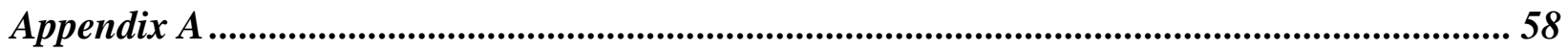

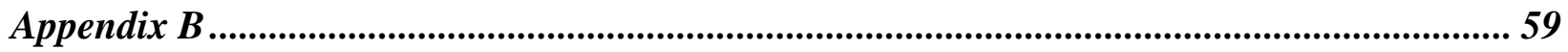

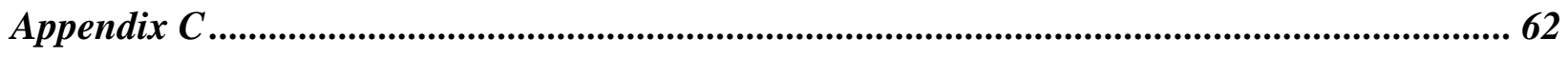

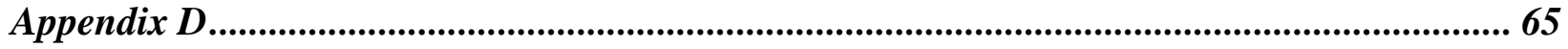

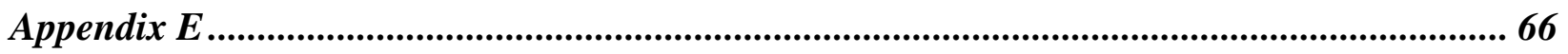

Resources.......................................................................................................................................................... 67 


\section{Chapter 1: Introduction, “Zivvie is my best friend"}

As an early childhood educator (ECE), I have observed children grow, develop and create their own knowledge through their social interactions with their teachers and peers in their classroom community. In the preschool years, as children become more independent they begin making their own choices regarding the activities they want to participate in and the children they want to engage with. I believe my role, as an ECE and as someone studying early learning environments, is to research and create environments that allow children to engage in inquiry and to become independent learners, to share their knowledge with others. The opportunity to participate and be an active member of a learning community should be available to all children regardless of ability.

Full inclusion allows all children regardless of ability to participate and be an active member of their learning environment. Bunch, Finnegan, Humphries, Dore \& Dore (2005) define full inclusion as:

Full Inclusion is closely associated with the Inclusive Model. It is characterized by routine placement of learners with disabilities, regardless of the type or degree of challenge to learning, in regular classrooms of community schools alongside age appropriate typical peers. In fully inclusive regular classrooms learners with disabilities receive acceptance and respect as would any other learner (p.34).

This definition implies that all children are entitled to an equal education and that difference is recognized but not discriminated against. My personal definition of inclusion incorporates the notion that every child should have an equitable opportunity to become an active member of a learning community, play with their peers, and participate in all learning experiences in the classroom. For the past 25 years, I have advocated for inclusion both on a personal level, as a 
parent of a child with disabilities, and as a professional educator. In my practice, I have witnessed children with severe disabilities excluded from becoming an active member of their early learning community. As a researcher and ECE, I want to explore and understand how children with severe disabilities, through their social interactions with their peers, could become a full and active member of their early learning community.

This paper explores one child's story, through the lenses of both her parents and those who care for her in a preschool daycare setting. In this effort the study will review current research on social interactions and autonomy, as well as social models of inclusion, Adaptive Design, parents' attitudes and beliefs regarding inclusion of their children, research regarding social interactions between children with severe disabilities and their peers, and the research on models to promote social interactions. 


\section{Chapter 2: Literature Review}

\section{The Importance of Social Relationships}

Social interactions are important to a child’s development. Everyday, children develop friendships with those around them, through their social interactions with their families, teachers, and peers. Friendships in preschool classrooms develop through social interactions between peers (Batchelor \& Taylor, 2005; Guralnink, 1999) and this supports the child's development in a learning community. The effect of these social interactions on the child and their development is well documented (Harper \& McClusky, 2002; Katz \& Galbraith, 2006; Odom, 2002). Children who have positive social interactions with adults and their peers develop a sense of belonging and acceptance of others, as well as positive attitudes, values and increased skills (Harper \& McClusky, 2002; Katz \& Galbraith, 2006; Odom, 2002).

The importance of the social context of learning is reinforced by Vygotsky's social cultural theory which notes that children learn through social interactions with adults and their more advanced peers (Vygotsky, 1978). In the preschool years, children will learn socially acceptable behaviour through imitation and modelling: "Learning is fundamentally social and takes place within children's cultural contexts. During the early years, children learn through active engagement, activity, observations, experimentation and social interactions with others"

(Best Start Expert Panel on Early Learning, 2007, p. 14). And over-all, there is a consensus that children are developing physically, emotionally and cognitively as they play in their ELCC classrooms.

In the preschool years, play is an important feature of children's social interactions. Guralnick (1999) suggests that the type of play the children are engaged in can determine the connectedness between their social interactions. His three major dimensions of connectedness 
can be best described as passive play, interactive play and friendship (Gurlanick, 1999). Passive play could be described as onlooker or parallel play. The importance of these forms of play is that the children are in close proximity, and this type of play will evolve into more active forms of play such as associative and cooperative play, which would describe interactive play. The final type of connectedness is friendship. Both unilateral and reciprocal friendships are formed in the preschool years: "A unilateral friendship is said to occur when one child prefers a peer, but the peer does not show a similar preference for that child” (Gurlanick, 1999, p. 73). Reciprocal friendships are defined as “mutual preferences for one another” (Gurlanick, 1999, p. 74). Guralnick's discussion of the connection between play and social interactions is important because it suggests that children in early learning communities are making the choice of the peers they want to play with and who is their friend. It is also important for children to have the ability to make their own decisions and choices in the activities they want to participate in and in the peers they want to participate with: "[A]s children grow, they become increasingly competent and able to direct themselves. Children's sense of self is at least dependent on seeing themselves as capable and independent beings” (Chaille \& Britain, 2003, p. 8).

In the preschool years, the child begins to move away from adult directed relationship towards a peer-based model. In quality inclusive programs, research suggests that children with disabilities when actively included with their peers preformed better, exhibited more cognitively mature forms of play and developed more positive interactions with their peers compared to children with disabilities in segregated classrooms (Katz \& Galbraith, 2006; Harper \& McClusky, 2002). According to Odom (2000), in 1998, the United States Department of Education reported that over $50 \%$ of preschool children with disabilities were enrolled in some type of inclusive preschool program. As well, researchers agree that all children, regardless of 
ability can benefit from social interactions with their peers and all children should have an opportunity to attend a full inclusive ELCC (Leyser \& Kirk, 2004; Stahmer, Carter, Baker \& Miwa, 2003).

Accordingly, social relationships are a strong concern for parents whose children had severe disabilities, and many worry that their children may not form meaningful relationships comparable to those of typically developing children (Leyser \& Kirk, 2004; Stahmer et al., 2003). Although friendships and social interactions do occur in inclusive preschool classrooms, according to several research studies, children with disabilities do not usually form the same friendships or have the same peer interactions as their peers have with their typically developing peers (Batchelor \& Taylor, 2005; Brown \& Bergen, 2002; Guralnick et al., 2007; Odom, 2002; Odom, Zercher, Li, Marquart, Sandall \& Brown, 2006). As well, children with disabilities spend more time with adults in the classroom and less time with their peers (Odom, Brown, Schwartz, Zercher, and Sandall, 2002). In an attempt to rectify the situation, there are several strategies used in inclusive classrooms to support children with disabilities to have positive social interactions with their peers to promote and develop friendships.

Inclusive classrooms can support positive social interactions through their physical and social ecologies (Katz \& Galbraith, 2006). Physical ecology is defined by the characteristics of the classroom and what materials are found there and social ecology is defined by the interactions between children, their peers, and adults (Katz \& Galbraith, 2006; Odom \& Bailey, 2001). Current strategies to increase social interactions between children with disabilities and their typically developing peers appear to be embedded in either a medical model framework or a social model framework. The strategies set in a medical model framework look at adapting the child as close as possible to meet the norms of society. These strategies are teacher-directed. The 
researcher or the teacher directs the social interactions between peers, as they choose a typical developing child and train them to be a peer model for the child with disabilities. The current research discussing the different types of peer modelling and their success are in the literature review (Batchelor \& Taylor, 2005; Gena, 2006; Stanton-Chapman et al., 2008).

It is important to note that, in the social model framework, the emphasis is on recognition of the child's abilities and making accommodation to the program to meet the child's needs. As Grenier (2010) states:

The social model centers on the concept of accommodation and the need to restructure mainstream schooling practices to ensure that all learners belong to an educational community. While the model does not deny the existence of impairment and/or physiological differences, judgements are not necessarily imbued with the same sense of good and bad displayed by the medical model (p. 389).

The research regarding changes to ecology of the classroom is discussed in the literature (Katz \& Galbraith, 2006; Kim, 2005; Odom, 2002; Aguiar, Moiteiro \& Pimental, 2010), but there is limited research studying how adapting the physical ecology of the classroom to meet the needs of a child with disabilities can change the social interactions between the child and their peers. It is the social model framework that more than anything informs the inquiry, and situates Adaptive Design as a crucial element in the creation of fully inclusive early learning environments for all children.

Research regarding Adaptive Design and social interactions is emerging, so I chose a narrative inquiry method to explore Zivvie’s story, in order to initiate a dialogue between Adaptive Design and the social inclusion model that will inform both future research and 
professional practice, and help others understand how it can benefit the child with disabilities in an inclusive classroom environment.

\section{Current Research on Social Interactions in Inclusive Environments}

There are concrete benefits for a child with severe disabilities who has the opportunity to engage in social interactions with their peers in a fully inclusive program. In an inclusive preschool classroom the child is able to be with their peers for extended periods of time. This allows all the children enough time required for them to interact and learn from their peers as they model and imitate the more advanced play of their peers (Odom, 2000). Several research studies suggest that when children with disabilities are placed in an inclusive classroom they exhibit more cognitively mature forms of play (Kim, 2005; Katz \& Galbraith, 2006). An important part of this equation is that when a child has positive social interactions friendships can develop. These friendships support numerous aspects of a child's development including their socio-emotional development (Guralnick, Neville, Hammond \& Connor, 2007). For all children, having the opportunity to be involved in an ELCC program allows them time to interact with peers to support their development. For children with disabilities, this opportunity is all the more important, as they often lack the chance for meaningful interactions with their peers in other settings.

\section{Parents’ Attitudes and Beliefs on the Benefits of Inclusive Settings}

Parents are the ones who make the decision to enrol their child with disabilities into an inclusive ELCC program and understanding what parents' beliefs and attitudes are regarding inclusion is important when exploring the complex puzzle of social interactions and the development of friendships for children with disabilities. Several key findings regarding parents’ beliefs and attitudes towards inclusion were present in the literature reviewed for this paper. 
Parents whose children had mild to moderate disabilities thought that inclusion would help their children's socio-emotional development, and the parents felt that their children were able to benefit from the interactions with their peers (Leyser \& Kirk, 2004; Stahmer et al., 2003). Both, parents who had children with disabilities and parents with children without disabilities, discussed how inclusion would help their children in the inclusive classroom become more accepting and sensitive to children with individual differences (Leyser \& Kirk, 2004; Palmer \& Fuller, 2001; Vssel et al., 2007). As well, Palmer and Fuller (2001) observe that parents' statements revealed that they were supportive of inclusion and felt their child would experience improvements in both academic and functional skills due to higher expectations and stimulation found in the general classroom. Parents of children with and without disabilities are enrolling their children in inclusive ELCC programs for their children to be actively involved with their peers. Overall, parents with a child with disabilities and parents with a child without disabilities were in favour of inclusion (Garrick Duhaney \& Salend, 2000; Palmer \& Fuller, 2001; Leyser \& Kirk, 2004; Stahmer et al., 2003; Vssel et al., 2007).

Beside these positive observations, there are concerns that need to be explored and addressed. Parents in all of the studies reviewed consistently expressed concerns for the quality of teaching and the support their child would receive in an inclusive ELCC classroom (Garrick Duhaney \& Salend, 2000; Leyser \& Kirk, 2004; Palmer \& Fuller, 2001; Stahmer et al., 2003; Vssel et al., 2007). The concern was greater for families with children who had moderate or severe disabilities. Parents of children with severe disabilities felt that their children required more care and attention then it was possible for an inclusive classroom teacher to offer (Palmer \& Fuller, 2001) and they expressed concerns that their child may experience social isolation and negative attitudes (Garrick Duhaney \& Salend, 2000; Leyser \& Kirk, 2004; Palmer \& Fuller, 
2001; Stahmer et al., 2003). As discussed by Leyser and Kirk (2004) many of the comments from parents with children who had severe disabilities revealed that they continue to struggle with the ideology of inclusion and what was best for their child's cognitive, physical and socioemotional development. Parental concern for their children, regardless of the presence of a disability, in terms of social interactions, seems to be based on the severity of the child's disability and is compounded at each point by uncertainty regarding the level of support their child will receive in an inclusive learning environment.

\section{Social Interactions and Friendship Development}

Although friendships and social interactions do occur in inclusive preschool classrooms, review of several research studies suggest that parents of children with disabilities were right to be concerned that their children may experience social isolation as children with disabilities do not form the same kinds of friendships or have the same peer interactions as their typically developing peers (Batchelor \& Taylor, 2005; Brown \& Bergen, 2002; Guralnick et al., 2007;

Odom, 2002; Odom et al., 2007). Several studies suggested that children with moderate to severe disabilities may have a harder time with social interactions, than children with mild to moderate disabilities (Batchelor and Taylor, 2005; Guralnick, 2007; Odom et al., 2007). Odom (2002) however, notes that all children suffer from rejection, in some form or another, in the preschool years. Typically developing children were rejected by their peers $10 \%$ of the time and children with disabilities were rejected by their peers $33 \%$ of the time (Odom, 2002). Although this is only $1 / 3$ of the population of children with disabilities, research also suggests that those children with disabilities that are not rejected by their peers are often given subordinate roles (Janson, 2001, 2007). Meyer (2001) also noted that their peers rather then being an equal might see children with moderate to severe disabilities as needing protection or requiring care. The benefits 
of social interactions in an inclusive classroom would be lost to a child with disabilities if they were not perceived to be an equal by their peers.

Children may not be perceived as an equal to their peers if they are unable to actively participate in the ELCC program. For children with motor impairments, the assistance they received from adults might lead to a classroom experience that is driven almost exclusively by the adult and not the child (Odom et al., 2002). Additional research suggests that the child with severe disabilities lacks the autonomy of her peers and is more dependent on adults to assist them in the activities and/or aid them as they moved from one activity to another activity (Harper \& McCluskey, 2002; Katz \& Galbraith, 2006; Kim, 2005; Odom et al., 2002). Having an adult support a child with severe disabilities changes the social interactions and play between these children and their typically developing peers (Harper \& McCluskey, 2002; Katz \& Galbraith, 2006; Kim, 2005; Odom et al., 2002). Kim (2005) more specifically notes that in her study there was a distinct difference in the type of play the child participated when accompanied by his educational assistant compared to the type of play the child was engaged in once the child's adult educational assistant had left for the day. His interactions with his peers increased significantly when the child had the autonomy to move around without his teaching assistant, and Kim (2005) notes that the adult's presence also hindered the spontaneous social interactions between the children. When supported by an adult, a child does not have the autonomy to make his or her own choices regarding the activities or the children that they want to play with, how they initiate and negotiate the social interaction, or to engage in spontaneous interactions as they arise. It is critical for researchers, educators and parents to recognize and develop strategies that promote and sustain positive social interactions between a child with disabilities and their typically 
developing peers that are child-directed so that children are able to have the kinds of autonomous social interactions we hope that all children will have.

\section{Current Research on Strategies to Promote Social Interactions}

In order for children to benefit from social interaction with their peers children need to be able to be considered equal members of the classroom community by their peers. This literature review explores two different types of strategies that have been used with the aim of increasing the social interaction opportunities between children with disabilities and their peers in inclusive classrooms.

\section{Peer modelling.}

Peer modelling is a teacher-directed strategy, based on a medical model framework used by some researchers/educators to support the development of social interactions between children with disabilities and their peers in inclusive preschool classrooms (Batchelor \& Taylor, 2005; Gena, 2006; Stanton-Chapman et al., 2008). With peer modelling, children with more advanced cognitive skills compared to their peers with disabilities are paired together in this strategy. Several studies reviewed used some form of peer-model training (Batchelor \& Taylor, 2005; Gena, 2006; Stanton-Chapman et al., 2008). It is the researcher or the teacher who chooses a child to be the peer model and conducts the training of the peer model. The results of these studies varied depending on the form of training given to the peer model; from a significant increase (Batchelor \& Taylor, 2005; Stanton-Chapman et al., 2008) to a moderate increase in peer interactions (Gena, 2006). Batchelor and Taylor (2005) used the 'Stay, Play and Talk Program', which used joint attention regarding a toy the peer was holding to initiate a conversation between the children. They found that by using this program there was an increase in the amount of child-initiated interactions between the typically developing child and the child 
with disabilities (Batchelor \&Taylor, 2005). These research studies point to adult initiated and directed strategies that have the potential to increase the level, though not the quality of social interactions between peers in an inclusive classroom. The strategies, however, require a teacher or researcher to direct how the peer model would interact with the child with special needs. Guralnick (2001) concludes that many of these kinds of adult-initiated programs and directed programs to promote social interactions may only have a short-term effect. One of the potential reasons is the lack of choice, on the part of the children involved, in most aspects of the process and interaction. There was limited discussion regarding child-directed social interactions between peers, or if this peer-modelling approach actually increased spontaneous peer-to-peer social interactions, or if it was sustained after the adult influence was removed. The teacher or researcher chose the peer model that the child with disabilities would play with and by doing so, removed the child's autonomy to choose their activities and their playmate. There is concern that without promoting a child's opportunity for autonomous choice in terms of how the child engages in social interaction that there will be limited opportunities for the child to develop fully as a social actor (Nolan, Raynes-Goldie, McBride, submitted).

\section{Environmental accommodations.}

A second strategy, based on the social model framework, is to make accommodations to the physical classroom environment and the program in order to provide the child with opportunities for autonomy to make their own choices of where and with whom they wanted play. This child-initiated/directed strategy promotes social interactions between peers by making changes to the early learning environment and the adaptive equipment the child with severe disabilities uses to engage with that environment. The following research studies discuss how the children's environment has an impact on the social interactions of children in an inclusive 
classroom (Aguiar et al., 2010; Katz \& Galbraith, 2006; Kim, 2005; Odom, 2002). For children with moderate to severe disabilities, the environment plays a factor in how the child, who uses adaptive equipment, is able to explore their classroom and participate with their peers in the different learning centres (Aguiar et al., 2010; Kim, 2005). A higher quality rating was given to centres that were accessible with well-designed layouts that allowed movements of staff and children to participate in as many activities as possible (Irwin, Lero \& Brophy, 2004). As well, Kim (2005) discusses, in her study, how the child was able to use his walker independently to participate with his peers in the dramatic play centre. The use of adaptive equipment allowed the child his autonomy to choose where he wanted to go and with whom he wanted to play with. Children are not able to imitate, model and learn from their peers if they cannot get to the area where the children are playing. The social model framework, acknowledges that it is the set up of the early learning environment that can promote or hinder children’s ability to have social interactions with their peers and that factors supporting choice and autonomous interactions are key.

\section{Adaptive Design}

It is not only the physical environment that is significant to the development of social interactions between children but the materials and equipment used by the child with disabilities is crucial. In order to understand how best to implement a strategy that seeks to modify the environment to best support a child’s specific needs. By closely observing how children are able to move and what their interests are, designing the environment and providing the materials that will allow children to explore, create and share their knowledge has the potential for peer interactions based on mutual interests and affinities (DiCarlo \& Vagianos, 2009). Higher quality centres based on the ECERS analysis performed by Irwin et al. (2004) were likely to have 
specialized equipment and materials in the centre that were readily available and that for some children specialized material or equipment is necessary to enhance their developmental capacities to ensure their full participation in the program. An emerging perspective that supports inclusive learning environments is Adaptive Design. Adaptive Design is:

The process, techniques and philosophy of creating custom adaptations for children with disabilities out of readily available materials, largely cardboard. It is rooted in the notion of user-initiated design, whereby the design process starts with the user and his/her particular needs and goals, and the role of the designer and fabricator is to be responsible for working to meet the needs and goals of the user. Adaptive Design can be seen as a form of action research, in that the inquiry process is dedicated to a specific goal or outcome that may not be generalizable or transferable (Experiential Design and Gaming Lab, 2011, http://edgelab.ryerson.ca/adaptive-design-studio/).

Adaptive Design has its roots in the Perkins School for the blind, and has been pioneered by Alex Truesdell at the Adaptive Design Association in New York for over a decade (Tomascoff, 2009). Adaptive Design requires that all who are caring for the child in an early learning environment work together as a united team to support the development of tools and adaptations specifically created for a single child based on close observation of the child's goals, needs and interests. Not all the objects used in my study were created by members of the Adaptive Design Association, however they all embody the ideas of Adaptive Design and reflect my goals for inclusive education. For this inquiry adaptive designs are defined as the individualized custom objects specifically designed to be used by the child to support her individual needs that are considered accommodations to the early learning environment. In order to create adaptive designs, consultation and approval from the parents is required, as they must work in partnership 
with the staff of the early learning centre, occupational therapists and the design team. Irwin et al. (2004) discuss that the quality of the inclusion program is strongly related to the characteristics of the staff that work within centre and the use of resources to create an environment that supports inclusion. It is possible for the parents and educators to be the centre of the design team or actually design and create the objects themselves, though often there is a need for assistance in fabricating materials. Finding an ELCC program that has a high quality program to meet the needs of a child with severe disabilities is another piece to promote social interactions with their peers. 


\section{Chapter 3: Methodology}

The key questions that guide this narrative inquiry are: What impact does the introduction of adaptive designs have on the social interactions between typically developing children and children with disabilities in an inclusive early learning environment? What was the nature of these interactions? What are the outcomes of these interactions? How might these outcomes impact future adaptations for children with disabilities?

\section{Strategy}

This research study is the story of a preschool girl with severe disabilities, it tells the story of her life in an ELCC learning environment. "Narrative inquiry is stories lived and told," (Clandinin \& Connelly, 2000, p. 20). The research focuses on personal stories of parents', teachers' and supervisor's thoughts, memories and perspectives that I used to create Zivvie's story. I employed narrative inquiry methodologies in this study because those who care for Zivvie can best describe her social interactions with her peers. Narrative allows the researcher a way of understanding others experiences through their stories by allowing the telling and retelling of personal stories, and narrative inquiry using personal stories provides researchers a rich view of those experiences (Webster \& Mertova, 2007). As Barret (2009) suggests narrative inquiry is a collaborative work shared between the researcher and the researched where the researcher is the storyteller relating the story lived by the researched. Bloor and Wood (2006) suggest the one of the strengths of narrative inquiry is that we are natural storytellers and that narrative can become a form of social action. As well, Bruner (2002) suggests that in order to gain knowledge of others and ourselves we need to explore the world of others and listening to the narratives can do this, in order to provide “alternative maps and different emplotments regarding disability and impairment that displace the tragedy story, that challenge and resist 
social oppression and that allow different body-self relationships to emerge (Smith \& Sparkes, 2008, p. 18). Listening to others experiences can bring about change. Using narrative inquiry for this research study allows Zivvie’s story to be told by those who care for her, and by telling Zivvie's story, I hope it will give power to their collective voices, for the purpose of opening a dialogue regarding Adaptive Design and how it can benefit a child with disabilities.

\section{Criteria and Sample Selection}

The criteria for this research study, was a child who used adaptive designs and attended an inclusive ELCC, and her caregivers, which required that I use the non-probability approach of convenience sampling. Non-probability sampling involves selecting participants for a specific reason not for mathematical probability (Bloor \& Wood, 2006). By using this approach I did not recruit participants from the population as a whole. There are several ethical concerns related to this form of sampling. With this type of sample the data collected will not be able to be generalized to the population as a whole, as it will represents the sample that was recruited. By limiting the sample population to the parents, teachers and supervisor it excluded other perspectives from this narrative inquiry, however since limiting the number of participants was required to meet the criteria of this research study, I do not think this poses any difficulty in terms of the validity of the study.

\section{Recruitment}

After receiving ethics approval to conduct this study, I contacted an ELCC in the Greater Toronto Area that has a policy for inclusion of children with disabilities. One centre agreed to allow the research to be conducted on their premises. As the researcher, I asked for the opportunity to place a recruitment letter (see Appendix A) in the centre. A meeting with prospective families who demonstrated an interest in participating in the research was arranged. 
The purpose of this meeting was to provide information to the prospective families. The parents who attended the meeting and met the research criteria were invited to participate in this research study.

\section{Participants}

Participants were asked to provide informed consent in order to meet with the ethical principle of informed consent. According to Boeije (2010) informed consent is intended to allow the participants an opportunity to understand the risks and benefits of the study with full knowledge of the purpose of the study prior to agreeing to participate. Zivvie's story could not be told without the participation of her parents, teachers and supervisor who provided their informed consent.

One family who had a child with disabilities agreed to participate in the study. The family consisted of a mother, Madeline, father, Arthur and one child, Zivvie a daughter who has severe disabilities. The researcher then asked the supervisor, and the teachers of the child if they would like to participate in the study. The supervisor, Cheryl and two teachers, Adam and Marcus, agreed to participate. The supervisor manages the centre that the child is enrolled in and the teachers worked with the child on a daily basis in the preschool room.

The participants were informed in detail about the purpose of the research study, how the study would be conducted and the tools and strategies that would be used. The risks and benefits of the study were also presented to the participants. According to Ryerson REB protocols, the participants were informed that they had the opportunity to withdraw from the study at any time. They were also informed that if they chose to withdraw it would not affect their relationship with the ELCC program, or with the University affiliated with the research. Each participant was provided with a letter outlining the study and a consent form to participate in the study (see 
Appendix B for parent consent and Appendix C for supervisor and teacher consent forms). The participants were asked if they had any questions for the researcher prior to signing the consent form to participate in the study. As Zivvie was a preschool child, three years old, at the time of the research data collection, she was too young to provide her written consent. However, I felt it was crucial to receive Zivvie's assent, as it was her story that was being told. After the parent's provided written consent for Zivvie to participate in the study she was asked to provide her assent to allow her parents, teachers and supervisor to tell her story (see Appendix D for child's assent form).

\section{Setting}

This research study is set in an ELCC, in the Greater Toronto Area. The purpose for choosing this setting was that they had an inclusion policy, were willing to allow the research to be conducted, and agreed to post the recruitment letter for this study. Though, I was familiar with the program having worked and done other research studies at this facility, this was not a primary motivator for choosing this site for the research. However, having this familiarity with the ELCC community helped me to access the parent population for recruitment purposes. After receiving ethics approval to conduct this study I asked permission to use the centre's classroom to conduct the interviews. In my previous research work I found that conducting interviews in a familiar environment was important to make the participants feel comfortable and confident enough to feel that they were able to share their stories. Though there are potential concerns regarding the use of this setting. One concern is that the setting was not representational of the province or country as a whole. By informing the public of where the study took place and the reasons for using this setting for this research study I am addressing these concerns. 


\section{Data collections tools}

In order to collect the stories from the parents, teacher and supervisor I used three data collection strategies; personal unstructured interviews, written responses and observations. The purpose of using several strategies was to collect the participants' stories from differing perspectives and triangulate the information. Cresswell (2009) reports that by using different data sources to justify the themes presented it can be seen as adding validity to the research study. Bloor and Wood (2006) argue that social scientists can validate their data by collaborating

findings from different sources from the same participants. For the purpose of this research study gathering the participants' stories using personal interviews, journals and observations helped to validate the stories presented and the participants and I felt that the process was meaningful.

\section{Personal non-structured interviews.}

Personal interviews represent an "elicitation of research data through the questioning of respondents” (Bloor \& Ward, 2006, p. 104). And using unstructured interviews, according to Frankfort-Nachmias and Nachmias (2000) allows the researcher to bypass the restriction of being limited to a set of questions in a predetermined order. The enquiry for this project is very exploratory and emergent so having a fixed process of inquiry might miss novel or emergent strands. Open-ended guiding questions were presented to the participants to draw out their story relating to this research study. With minimal direction on the part of the researcher, participants are encouraged to share their experiences and describe events that are significant to them whatever manner they feel comfortable with.

There are several advantages and disadvantages to using personal interviews. Neuman (2006) reports that face-to-face interviews have the highest response rate. When it comes to faceto-face interviews another advantage is that the researcher is able to also observe and document 
nonverbal communication of the participants. Disadvantages, according to Neuman (2006) include the high cost and time involved to interview all of the participants and a potential for interviewer bias leading the subject. Frankfort-Nachmias and Nachmias (2000) suggest that the characteristics of the interviewers and differences in interviewer technique may affect the participants' answers, but this is not a problem when a single interviewer is conducting all interviews. For the purpose of this study I conducted the personal interviews (see appendix E for the interview protocol). This was done to eliminate differences in the technique used by multiple interviewers.

\section{Written responses.}

The participants were asked to write their responses using the same protocol from the personal interviews. The purpose of using a protocol was to help guide the written stories. This along with the interview information helped collaborate Zivvie's story presented by the participants. The use of written responses for this research study was provided in order to offer the participants a different strategy to tell their story, as an interview revealing personal information may be difficult. Using written responses for collecting the participants' stories is according to Clandinin and Connelly (2000) an empowering way for the participants to give accounts of their stories and written responses often take on a different quality that is more reflective in its nature.

\section{Observations.}

Observational data was collected during the course of this research study. This data was comprised of field notes, memos written during the interview process and used existing observational data written by the teachers to develop programming for the children in the ELCC. Verbal assent and written consent from the parents, teacher and the supervisor was received to 
use the collected data. The observational data collected was reviewed and was used to support Zivvie’s story told by the parents, teachers and supervisor.

\section{Methods of Data collection}

The participants were recorded with a digital audio recorder providing an accurate account of the participants' stories. The recording was transcribed to allow the researcher an opportunity to review and code reoccurring themes found throughout the research study, and improve the reliability of the information because it does not rely on the researcher to take accurate notes or to only record information based on their personal bias (Bloor \& Wood, 2006). However there is the ethical issue of anonymity as the participant's voice is recorded. This issue was disclosed to the participant's prior to their participation so they were fully informed prior to giving their consent. Each participant prior to being interviewed was asked to provide his or her assent to the audio recording. All the participants agreed to the audio recording and notes were taken to record the body language of the participants during the interview. Assent was given by the participants to incorporate these notes into the research study. Finally, the participants were given an opportunity to read the transcriptions to verify the accuracy of Zivvie's story presented in this research study.

\section{Data Organization}

To maintain the integrity of the participants' stories that were collected for this research study proposal, I used the following data organizational strategies. From the start, upon receiving the participants' consent to participate in the research study, they were given an identification number and a pseudonym. This number was placed on the back of the consent form and was used on all subsequent data collected. For example RS P-1 was given to the first participant and a pseudonym was given. The consent forms with the identifying number and pseudonym were kept 
separate in a locked cabinet from the gathered information. This helped maintain the anonymity of the participants and kept the participants identity confidential by ensuring that the participants name and other identifiers are not attached to the data (Boeije, 2010). The digital audio recordings were identified with the participant's number and pseudonym AR PP-1 (audio recording - participant 1). The transcriptions of these recordings were also numbered to match the previous number scheme used throughout TAR PP-1 (transcription audio recording participant 1). The written transcriptions were stored together with the digital file. Each participant's information was stored in a separate file. By keeping the recordings together with the transcription, I was able to check the transcriptions to make sure there are no obvious mistakes. This assisted in maintaining the truthfulness of the data. All of my written notes and memos that related to a particular participant, were numbered to reflect this numbering scheme and they were placed them in each of the individual's files. All copies of the information used was numbered accordingly and when no longer needed was placed in the participant's individual file. This was done to prevent wrongful identification of data. All of the data will be stored for a period of two years in a locked file cabinet in my home office.

\section{Data Analysis}

Data analysis in qualitative research according to Boeije (2010) is taking the data and segmenting into parts then returning those parts back into a coherent whole. As Cresswell (2009) states data analysis is an ongoing process that is concurrent with the collection of data. Maintaining the integrity of the participants' stories requires segmenting the data and reassembling it from the angle of the research questions and the purpose of the research study. It requires that the researcher to continually reflect on the information collected and it's meaning. For this project, the reflection was in the form of memos written on the review of the interview 
transcripts before the next personal interview. This data helped with determining coding of the data into themes. Boeije (2010) suggests that there are three starting procedures used for qualitative analysis. These three procedures, constant comparison, analytical induction and theoretical sensitivity served as the basic framework to proceed with the analysis. Analytical induction is, “a procedure for analysing data which both requires the analyst to work systematically and aims to ensure that the analyst's theoretical conclusions cover the entire range of available data” (Bloor \& Wood, 2006, p. 13). For the purpose of this research study I analyzed the participant's stories with reference to the purpose of this study and the research questions. To accomplish this, I coded the information in the participants' stories to draw out themes that were representative of all the collected stories. Applying meaning to the data using key words or phrases defines coding. For the first stage, I read and then reread the data to become familiar with the participant's stories. As the data became familiar I started writing memos and notes that came from the data. These themes were used to deconstruct the data and then were written up to reconstruct the stories. For the purpose of this research, it is at this point that the data was presented to the participants again for checking. This allows the participants whose voice is being presented to determine the accuracy of the data upon reconstruction. This helped maintain qualitative validity, which according to Cresswell (2009) means that the data is checked for accuracy using several strategies. Following these procedures for this research study I have created a reconstruction that is trustworthy. 


\section{Chapter 4: Zivvie's Story}

Zivvie's story starts long before her move from the toddler room to a preschool

classroom. It starts when her parents were looking for quality childcare for their daughter:

Madeline: We were looking at different daycares before [Zivvie] was born, when I was pregnant and we didn't actually know at that time that she would be born with any type of special needs, so we were looking at different lab schools just because we liked the idea of having the extra staff and the extra supports and the extra students and all that. Zivvie's parent's search turned to an inclusive ELCC after she was born. As discussed in the literature review, different levels of quality can be found in ELCC. This was made apparent as her parents investigated the centres available to them that would meet their daughter's needs. As Madeline states:

We did initially go with another daycare that I shall not name that we were very displeased with, and the attitude was more that [Zivvie] could be part of the classroom by watching the other children play, and we didn’t like that attitude... you know she would just be there to watch.

The ELCC where this research was conducted was a more suitable place for Zivvie's parents. From the very first meeting, Zivvie's parents felt that their daughter's needs would be meet: Madeline: Immediately as soon as I visited the centre and I meet [Cheryl] and I met some of the teachers I could see that all the children's needs are met at whatever their level is.

This was very important to Zivvie’s parents because she is, as her parents describe, a child who has severe disabilities: 
Arthur: so kids with [a rare chromosomal disorder] are very small in stature, they have developmental delay, they have delay in standing, sitting... all the milestones. [Zivvie] in particular had a lot of difficulty reaching and grasping for things... [and Zivvie] has a visual impairment.

Madeline: She is considered blind with vision.

Arthur: She does manage to hear and navigate through her world in an oral and auditory sense.

Madeline: She is non-verbal, so that's a really big thing particularly with communication with her peers and her teacher... she communicates through sign language and body movements and facial expressions. She also has a slew of medical conditions. Arthur: [Zivvie] is not able to sit independently so she needs special seating, and she is not able to walk without assistance. In terms of special needs [Zivvie] has highly, special needs, [Zivvie] is not a kid defined with mild or moderate needs... when you look at her objectively, she is pretty disabled but [Zivvie] does so much and [Zivvie] is able to do so much... she has so much personality. She is able to do so much.

The ELCC centre was chosen by the parents, because it has a policy for inclusion of children with disabilities. As the supervisor, Cheryl articulates it:

We are very fortunate here that we have both a staff and management that want to support full inclusion, and in fact have been forward thinking enough to write an inclusion policy that has a zero reject policy... I think in the last year and a half we worked really hard as a staff, working with her family and with [Zivvie] specifically on opening up the opportunities for her and the adaptive furniture design... Inclusion means 
to me that every child can attend regardless of ability and that there should be no limitations in the environment.

When each of the teachers who work with Zivvie told their stories, they expressed their own sense of what inclusion means to them:

Marcus: My belief about inclusion would be to have all children of all abilities to be included totally in the classroom in all areas so that all children have access to every activity whether it be painting or puzzles at a table and every child has access to those activities.

Adam: My belief in inclusion is that the classroom that the child is in, that the teacher in that classroom should do whatever is possible to fully include everyone in that classroom, using supports, using information from the parent, using their understanding of child development to make the child welcome and to be able to be involved in everything the classroom offers.

It is important to understand what the parents, supervisor and teachers' attitudes and beliefs are regarding inclusion, as it is the foundational to this study and to Zivvie's story. The parents discuss what inclusion means to them as they told their daughter's story:

Arthur: I think inclusion is not about kids, it is about a whole attitude and mind set about how you approach everybody. Because inclusion is about everybody, it is not just about a kid using a walker or a wheelchair it's about the kid who comes everyday. It's about how you do things for everybody not just [Zivvie].

Madeline: It's a lot about attitude I mean I have heard excuses before from other teachers, other places that they can’t include because they can’t afford this or that but it doesn’t cost anything to rearrange the room so the child can have access. It doesn't cost anything 
to care about the child and try to learn the best way to communicate with the child. Because you know the kids pick up on that attitude.

When the parents discussed what their expectations of the program were they made it clear that they did not want their daughter to be sitting on the sidelines observing other children they wanted their daughter to be actively involved with the activities and her peers:

Arthur: We liked the idea that she would be around the other kids... and this was confirmed once she got here and became part of the community and became part of the classroom.

Madeline: We see daycare not just as a babysitting service... we were seeing this specifically as an educational opportunity for [Zivvie], to socialize with other kids and get that kind of piece and so for her to benefit from that she obviously needs to be included in a very active kind of way.

As Zivvie's story unfolds, all the participants discussed the adaptive designs Zivvie used and the social interactions Zivvie had with her peers. This equipment was used to support Zivvie's physical needs. The infant/toddler equipment it was noted gave the impression that Zivvie was an infant or toddler not a preschooler. As Adam, her teacher expressed it also inhibited the interactions she had with her peers:

A lot of the equipment that [Zivvie] was using was kind of standardized infant material, which was getting more and more less age appropriate for her. There was a highchair, there was an infant excersaucer that she had outgrown, and a stroller, and I guess the teacher's arms. We didn’t have a lot to assist us having her join her friends at their level at the activities. The things like the excersaucer kept her separate from the children. In the way the children interacted with her was still as that of an infant even though she had 
progressed beyond that point so it was to get material to allow her to be involved with the other children at her level and that was more age-appropriate.

As Adam reflected, when the children viewed her in the infant/toddler equipment his perception was that the children saw Zivvie as an infant, and their behaviour towards her was not that of a peer. And when Zivvie was not in the infant equipment, due to her physical needs, the teachers in the classroom supported her, which also caused her to be perceived as an infant by her peers. Cheryl recognized this as she observed:

A child that needed someone to sit with her or had a piece of furniture that was really designed for an infant rather than a young child is limiting. Because it sets the tone for how others will approach her.

Zivvie's mother also reflects this in her story as she relays the following:

When there is an adult sitting behind holding [Zivvie] the play changes.

There was also the recognition from the teacher that the equipment the child was using as a toddler was no longer appropriate for a preschool room. As Adam describes:

Well the switchover came from wanting to have her, to have [Zivvie], be at the same level as the other children and for the material to be more age-appropriate.

All of the participants talked about the changes to more age-appropriate (this term was used by the participants in their interview and will be used to keep consistency) adaptive designs used by the child and how the interactions with the child's peers changed. One of the pieces of infant/toddler equipment, Adam talked about a highchair that was replaced by a wooden corner chair. The parents talked about how this chair was designed and built:

Madeline: The corner seat we had at home at the time because [Zivvie] was quite young and sitting was the biggest thing she was working on, was on the floor and had a little 
table for her to play and that was the design we had showed the teachers and [Cheryl] even thought of a better idea to make the seat so it fit the table with the other children so she is not in a corner by herself or on the floor. She is sitting at the table.

The corner chair allowed Zivvie to eat her meals and participate in activities with her peers at the same table not separately.

Adam: It started with the chair... to fit at the table so [Zivvie] would be able to sit at the table and eat with her friends and participate in activities at the table with her friends because otherwise she was at a highchair that was always kind of separate and above the other children.

The change of equipment from the highchair, which was not age appropriate, to the wooden corner chair eliminated a barrier to the social interactions between the children.

Cheryl: The barrier of having a piece of equipment that stopped her from being close to her friends now became a piece of equipment that brought her close to her friends.

This was true of other pieces of adaptive designs, which were constructed by student ECE interns at the EDGE Lab using the Adaptive Design techniques out of cardboard, using the schematics from the wooden corner chair. Adam identified in his story how Zivvie used these.

We have a cardboard version of the wooden chair that's much more portable that we can bring to the sandbox, one that we use in circles and other kinds of carpet activities. It was observed that this chair allowed Zivvie to play in the outdoor sandbox without a teacher supporting her. Madeline referred to this in her interview:

The biggest thing about equipment is that it allows [Zivvie] access to the other children and to play with the other children at their level, because the play changes when there is an adult sitting behind holding [Zivvie]. The play changes when it’s the child playing 
independently... [Zivvie] is sitting at the centre in the sandbox the same as any kid sitting at the sandbox and so they interact with her that way versus if there is an adult sitting behind her at the sandbox. It is very different to a child.

This statement from Zivvie's mother provides another of the key pieces to this story that adaptive equipment gave the child her autonomy. As discussed giving the child autonomy is essential to their ability to choose who they want to interact with and where they want to play. Madeline goes on to say:

The biggest thing that it provided and appropriately at the appropriate age, you know she got her walker at two and she was using her stander around then, you know right at the age when kids should be more autonomous and less dependent on adults, that sort of thing.

Another piece of adaptive designs used by Zivvie in the classroom was a walker. All the participants spoke of this in their stories. The parents discussed how Zivvie was introduced to the walker. From the first use the child was able to control her movement.

Arthur: She's not able to walk without assistance, so she uses one walker that she uses primarily indoors and one that she uses primarily outdoors or in a larger setting because it's a larger walker and she does really well now. Actually, that was one of the things she really took to kind of right from the beginning but she definitely wanted to walk and she wanted to the first time we put her in it and she took a dozen steps across the room and everybody was amazed at that because it was not typical, so [Zivvie] obviously wanted to move and she definitely does because when you put her in the walker, she's gone.

As the parents relayed how important the use of the walker was as it gave the child mobility. Marcus discussed how the mobility allowed Zivvie to go independently to activities and to make 
her own choices in activities she wanted to do as well as choosing the classmates she wanted to play with:

I have seen [Zivvie] move around the classroom. She is much busier. She is never idle. She is doing something. Since she started with these [adaptive design], she is able to go to the water table, she is able to go to the sand table, she is able to participate at group time, go to the computer where she can press buttons, and she can go to the paint easel. She can go to these areas on her own where as before she'd have to have more assistance from the teacher. She could go up, on her walker, and go to these areas where a teacher is sitting at a table and she can come up beside the teacher and join the activity that is going on and she is interacting with the teacher and the children but it is her choice to come over. Where as before she would have to be put in a chair and the children would have to come to her. So now she is making the choice to go to these activities that she has interest in.

Adam also commented regarding Zivvie’s independence and her ability to make choices not only with the activities she wanted to participate but how it also gave her access to her peers:

[Zivvie] became much more independent in her play. Where as before we would often kind of choose activities for her based on her interest we would actually physically move her from this activity to this activity, and with the new equipment it allowed her to choose her activities, it allowed her the freedom to move to materials that she wanted to play with, it allowed her to access new materials, it allowed her to function at activities with her peers.

Cheryl also noticed how these pieces of adaptive designs gave Zivvie her mobility and commented on the change in the way the children interacted with her: 
Then the new pieces of equipment, you know certainly when [Zivvie’s] stander came and her walkers, again it opened more and more options for her. She had mobility, she was the same size as the other kids when she was standing up, while petite she certainly was not an infant anymore, and that really changed how her peers looked at her.

The change in the social interactions with Zivvie and her peers was also revealed in the stories of her parents and her teachers. In his story Adam discusses how Zivvie would move to areas of the classroom where her peers were playing:

I've seen her move towards areas of the classroom where children are playing as opposed to other activities where she generally likes to go. An example of that is the block area today, where other children were building structures, building structures with the hollow blocks and the cardboard blocks, and she was interested in moving herself in there to play with them, which came a part of a social experience where the other children were stacking towers on her walker, for her to knock over. She wheeled herself to that area and started engaging with the other children.

Her parents also discuss the shift in the social interactions between Zivvie and her peers. As Madeline reveals in her interview:

I've seen that shift from being excited to be at school and be around the adults to being excited about school and being around her peers and her peers coming up to me telling me, “you know, [Zivvie’s] my best friend”. I think the equipment allowed that change because she wasn't as dependent on the adults and she could play with the kids. I noticed the other day, Zivvie came running over to see another child and he got excited and said “[Zivvie], came to see me”.

Arthur also discusses the interactions Zivvie has with her peers: 
One of the things I value right now is having one of the kids come up to her, have a little girl say “Zivvie’s my best friend”, because Zivvie’s not able to express that to us and to have another little girl think that Zivvie’s her best friend is wonderful. I think the peers came to view her more as an equal because you know before she had some of the equipment she had to be carried or supported whereas now her peers are seeing her as an equal. A different type of kid but that's just [Zivvie] to them and it's great. It's exactly what we want is [Zivvie] to be [Zivvie]. I mean [Zivvie] is always going to be a bit different from the typical preschooler or elementary schooler but we just want her to on equal footing with them socially.

Arthur goes on to discuss how the children in the classroom are also including Zivvie in their play. He expresses how they embrace having Zivvie as a playmate and the accommodations they make to play with her:

I think there has been an inclusion aspect there and not inclusion in the systemic sense, but in wanting to be involved in their play, but maybe because the kids are getting a little of it too. They're kind of setting things, helping to set things up for her too, like when I was in the room over there, the little girl had seen [Zivvie] was here and was setting things up for [Zivvie] to come play with them and getting excited about that.

Adam in his story also describes how the children in the room are making accommodations to play with Zivvie as an equal:

She is seen more as someone around their own age and they are that much more interested in interacting with her on a more age-appropriate level where as before they kind of go up and just pop materials for her play with on the excersaucer. Now they are including her, one example is where they built a block structure, I think it was a rocket 
ship and they asked if they could include [Zivvie's] chair so she could come into the vehicle with them, so she could sit up and actually play a game with them in the dramatic scenario, which is them not viewing the child as an infant but viewing the child as an equal.

Zivvie is also able to recognize and name her peers as Adam portrayed in his story:

We had an excellent activity performed... she was able to identify all the children in the classroom through pictures and through pointing, which shows us she is aware of their names, she's aware that these are her friends in the classroom and she will sign for friends.

As Madeline adds from her story, Zivvie is going and playing with her peers:

And for [Zivvie] you see her, once you put her in her walker she's off and running and wanting to go play with them and we joke because she barely has time to kiss us goodbye because she's off and after her friends, but that's how a three and half year old should be running off with their friends and saying 'see ya mom'.

Adam identified how the teachers adapted the environment to accommodate the adaptive equipment so Zivvie could ‘run’ after her friends:

Well with the equipment especially with the walker the classroom environment had to constantly be kind of tweaked to allow space to allow her to get around easily. We had to limit the amount of tables and really take in to consideration chairs blocking pathways, really taking into consideration all the pathways in the classroom and how easy it would be for [Zivvie] to get around the classroom.... It is a thoughtful arrangement to allow for all the children to be successful. 
Adam goes on to say:

We have a fabulous computer stand that allows [Zivvie] to come right up and use the computer easily and the other children as well, so it is not specifically for her the other children are able to use it as well.

Madeline also describes the computer in her story:

The computer was another piece that introduced her to using the computer. [Zivvie] is fascinated now with the computer at home and frustrated because it doesn't work the same. So that's the technology piece.

As Marcus relayed in his interview:

She can also go to the paint easel. It is angled for her to use instead of being more upright it is more of a 30-degree angle where she can put her hand out and reach and she can create her own colour creations with paint.

Cheryl adds to this:

The computer being added to the classroom, the opportunity to be able to paint at an easel beside a friend, really mind-opening opportunities for her and it has really allowed us to see that inclusion can happen

The teachers discussed how the adaptive designs were designed to meet Zivvie's needs in the classroom. As Madeline discussed when asked about the adaptive designs:

I mean there are lots of things with the equipment and things that the school thought of that we didn't even think of because we are not at school with her and her day at school is very different then her day at home. The things that are created at school they’ve seen a need for and they have gone ahead and created it and we didn't always realize there was necessarily that need because we don't see that. 
Madeline and Arthur convey this in their interviews; how the use of the adaptive designs has affected Zivvie’s physical, cognitive and socio-emotional development:

Madeline: Well I mean other than the socialization piece, there’s the big physical piece. I mean that's a big part of her day; she really needs to be up and around. We see her muscle tone increasing. We're hoping her lungs are getting better and I think a big part of that is because she is upright, she's moving around so she has the health benefits of being here. In every area, there have been positive gains.

Arthur: The emotional development too! Just being independent and relating to people in an age appropriate way. I think that's also aided by the equipment because she is not being carried around.

Madeline: I mean without her equipment her day would be very, very, different. She can’t grow or develop without that equipment.

Adam also commented on Zivvie's development with the use of adaptive designs:

I will go through the domains. In terms of physical development, Zivvie’s movement, wasn’t happening before. She was being held sitting, laying down a lot. Now she is spending that much more time walking, moving her legs, her core strength and her leg muscles. We saw much improvement in her ability to move herself around. In terms of cognitive development we are getting a greater sense of things that she's interested in, she is getting a chance to select activities. In terms of socio-emotional development she is able to be included with her friends at their level be it at the sand box or working at the computer or working at the table. In terms of language with her speaking with sign language the walker allows her arms to move and be able to signal her intentions, to 
communicate with us and her peers, where as when she was lying on the ground it was more tricky for her to coordinate her movements to make a sign for us to understand.

The participants' stories illustrate how the use of adaptive designs changed the social interactions between Zivvie and her peers in her early learning environment, from treating her as an infant to treating her as a friend and equal. 


\section{Chapter 5: Discussion}

Zivvie's story from the perspective of those who care for her illustrates how she became an active member of her early learning community in terms of her social interactions with her peers: being seen as, and seeing others as, friends. This research study's exploration of the use of several adaptive designs suggest that these designs, and the principles of Adaptive Design, provided Zivvie with an opportunity to be actively involved with her peers and gave her sufficient autonomy for her to be able to make choices regarding how she wanted to participate in her learning community and engage with her peers, as well as improved opportunities for her peers to engage with her. As well, there is indication that Adaptive Design concepts facilitated Zivvie's peers seeing her as an equal. This study also set out to explore the teacher's role in the social model of inclusion to observe and make accommodations to the environment and materials in the learning community to facilitate Zivvie's development. The participants openly shared their perceptions of Zivvie and her interactions with her peers as they discussed the adaptive designs used by Zivvie and the changes made to the classroom environment. From their stories, several themes emerged: the parents expectations of the program for Zivvie, the beliefs of the stakeholders regarding inclusion, the accommodations made to the program to support Zivvie's participation as a full member of the learning community, how the use of adaptive designs changed the social interactions between Zivvie and her peers and how this affected Zivvie’s socio-emotional, cognitive, and physical development.

In Zivvie's story the parents discuss what they expect from the ELCC program for their daughter revealing that they enrolled Zivvie into the ELCC program to socialize her with her peers and be an active participant in the program. One of the reasons parents choose to place their children in an inclusive ELCC was so their children would socialize and make friends 
(Leyser \& Kirk, 2004; Stahmer et al., 2003). The literature reports that children with disabilities when actively included with their peers in an inclusive classroom, perform better, exhibit more cognitively mature forms of play and develop more positive interactions with their peers compared to children with disabilities in segregated classrooms (Katz \& Galbraith, 2006; Harper \& McClusky, 2002). If a child is not actively involved in the program it inhibits the social interactions that can happen between a child with severe disabilities and their peers. Whether her parents were aware of this research or not, Zivvie's parents' expectations were that she would be actively included in all learning and social opportunities available in an inclusive ELCC. For Zivvie to be actively involved in the ELCC, however all stakeholders had to work together to meet her needs. In order to meet their expectations and for Zivvie to become a full member of her early learning community her parents enrolled her in an ELCC with a full inclusion policy that would support Zivvie’s needs and meet their expectations. Zivvie’s parents also were also looking for an ELCC that reflected their beliefs and attitudes regarding inclusion. In the telling of Zivvie's story, both of her parents reveal that they saw their shared attitudes and beliefs reflected in the attitude of the staff and that attitude was reflected in the programming and participation of the children in that ELCC. Several research studies note that parents had concerns that their child with severe disabilities would not receive the quality of teaching and the physical support they needed in an inclusive program (Garrick Duhaney \& Salend, 2000; Palmer \& Fuller, 2001; Stahmer et al., 2003). However, Madeline makes it clear that the ELCC where this research study took place was appropriate because it was evident that the children's needs were met. Irwin et al. (2004) suggest that full inclusion refers to centres that have an inclusion policy that embodies the principles of zero reject and full participation of children in activities. This was 
important to Zivvie's story as the ELCC where she was enrolled had a 'zero reject' inclusion policy that reflected the supervisor and staff's attitude and beliefs regarding inclusion:

Cheryl: We are very fortunate here that we have both a staff and management that want to support full inclusion, and in fact have been forward thinking enough to write an inclusion policy that has a zero reject policy.

The quality of the inclusion program is also strongly related to the characteristics of the staff that work within a centre and the use of resources to create an environment that supports inclusion (Irwin et al., 2004). Adam and Marcus highlight staff attitudes and beliefs and their willingness to include the active involvement of all the children, in all areas and activities using whatever supports and information from the parent to compliment their understanding of child development. For Zivvie, all the stakeholders had beliefs regarding inclusion allowing them to work together to support her learning and socialization in the classroom. This supportive environment was evident from Zivvie's story, my observations and from the individual program plan (IPP) reviewed for this research study.

The IPP was created from meetings that involved the parents, teachers, supervisor and additional resource team members. The focus of all the staff at the centre was on what Zivvie could do and what was required to make her classroom experience successful. From my observations, Zivvie was being actively involved in the program and this increased her opportunities to interact with peers in her class. The beliefs and attitudes of all the stakeholders reflect the social model of inclusion.

Another theme that was drawn from Zivvie's story was how accommodations were made to allow her to become actively involved with her peers. These accommodations in Zivvie's 
story include the early learning environment and the use of adaptive designs. According to Irwin et al. (2004) higher quality centres were likely to have specialized equipment and materials in the centre that were readily available. For some children specialized material or equipment is necessary to enhance their developmental capacities to ensure their full participation in the program (Irwin et al., 2004). As Zivvie’s story reflects she used several pieces of adaptive designs to support her needs.

The accommodations made to the physical environment and materials, were important to Zivvie as she uses several pieces of adaptive designs and other more standardized assistive devices to support her physical needs. Some pieces of adaptive designs such as her walkers were brought in from home. ECE students studying Adaptive Design in the EDGE lab as part of their internship created other pieces of equipment, the cardboard corner chairs, a multi-use easel and the computer desk. Zivvie's physical disabilities require the use of adaptive designs to support her in a sitting position, to walk and to play.

Arthur: [Zivvie] is not able to sit independently so she needs special seating, and she is not able to walk without assistance. In terms of special needs [Zivvie] has highly, special needs, [Zivvie] is not a kid defined with mild or moderate needs... when you look at her objectively, she is pretty disabled but [Zivvie] does so much and [Zivvie] is able to do so much... she has so much personality. She is able to do so much.

Research studies discuss how the children's environment might have an impact on the social interactions of the children in an inclusive classroom (Katz \& Galbraith, 2006; Kim, 2005; Odom, 2002; Aguiar et al., 2010). DiCarlo and Vagianos (2009) indicate that the staff should facilitate the play by observing the children and designing the environment that will allow children to explore, create and share their knowledge. Zivvie's story reflects on how important 
the environment was to her ability to interact with her peers. Through my own observations I noted that the pathways in the classroom were wide enough to support Zivvie's movements with her walker, and that she was able to access all the learning centres of the room.

I also observed that along the pathway materials were set up to allow Zivvie the ability to interact with these, while in her walker. The water table and sand box were able to accommodate both the stander and Zivvie's walker allowing her to independently move to these activities and participate without the support of an adult. As well as the walker it was noted in the observations that Zivvie used a wooden corner chair set at a table. This chair was used to support Zivvie at mealtimes and while she was participating at activities at the table. Two additional cardboard corner chairs made by the ECE students were observed being used by Zivvie in the early learning environment, one was used on the playground, to support Zivvie sitting in the sandbox, the other was used to support her sitting and participating in activities in the block centre and literacy centre. Zivvie was also observed using a stander at the sand and water table. The ECE students, to accommodate her walker, as well as use by other children, built the computer into a desk stand. The keyboard and screen were angled to make it user-friendly for Zivvie and her peers. Zivvie was also observed working at the easel that was designed specifically for her by the students based on observations of how she moved. It was created to allow Zivvie to work with her peers in the creative arts learning centre. The easel was designed to accommodate Zivvie's walker and set at an angle to support her physical needs. The accommodations made to the physical environment, were not static. As Adam discussed they were a thoughtful arrangement to meet all the children's needs in the classroom. These accommodations were important to Zivvie as they were made to accommodate her physical needs and support her in being an active community member of her ELCC. Zivvie's story reflects that the type of accommodations that 
were made with the use of adaptive designs could hinder or promote her active involvement in the program. The positive effect this had on the social interactions she had with her peers was another theme drawn from Zivvie’s story.

In Zivvie's story the initial accommodations made to support her in the preschool room when she transitioned from the toddler room, hindered her interactions with her peers. From Adam's comments the infant/toddler equipment did not allow Zivvie to be actively involved. Adam reflects that Zivvie's peers interacted with her as if she was an infant, not peer-to-peer as an equal. Cheryl and Madeline also reflected that when Zivvie was supported by one of the adults it affected the social interactions between Zivvie and her classmates:

Cheryl: A child that needed someone to sit with her or had a piece of furniture that was really designed for an infant rather than a young child is limiting. Because it sets the tone for how others will approach her.

Madeline: When there is an adult sitting behind holding [Zivvie] the play changes. Several research studies suggest that children with disabilities do not have the same type of social interactions with children with severe disabilities; children with disabilities were rejected more often by their peers than typically developing children (Odom, 2002) and children with special needs that are not rejected by their peers may be given subordinate roles (Janson, 2001, 2007). Meyer (2001) also notes that their peers rather than seeing the child with disabilities as an equal might see children with moderate to severe disabilities as needing protection or requiring care. In Zivvie’s story all the stakeholders discussed how the children treated Zivvie as an infant, interacting with her by placing a toy on her excersaucer and walking away.

Not only did the use of infant/toddler equipment limit Zivvie peers interactions, the equipment also limited her autonomy and her independence. Zivvie was dependent on her 
teacher to make choices of what she would do and with whom she would play with. Adam identifies this in Zivvie’s story:

We would often kind of choose activities for her based on her interest we would actually physically move her from this activity to this activity.

These actions reduced the time Zivvie spent with her peers. It was also a teacher-directed approach not a child-directed approach, as the teacher was choosing the activity for Zivvie. From the observational data it was noted that when her teacher supported Zivvie, her peers conversations were directed to the teacher not to her. The observational data also revealed that there was limited eye contact made directly to her and it appeared that the children did not recognize Zivvie as a peer. The research reviewed for this study supports these comments; having an adult assist the child with severe disabilities limits spontaneous peer-to-peer interactions (Kim, 2005). The staff recognized that the infant/toddler equipment that Zivvie was using was not age-appropriate and was affecting the interactions Zivvie was having with her peers. These accommodations were obstructing Zivvie's ability to fully participate in the program and it was excluding her from participating actively with her peers. This is important to recognize, that accommodations made with adaptive designs need to be age-appropriate, which is exactly what the stakeholders set out to create.

The stakeholders reflect in Zivvie's story the need to create the adaptive designs to pieces that were more age-appropriate but still supportive to meet Zivvie’s physical needs. From her story, Adam discusses the change in equipment and the introduction of Adaptive Design principles. The staff and parents looked at ways to accommodate and support Zivvie's needs but at the same time make the equipment age appropriate for a preschooler. Zivvie was provided with several adaptive designs, two walkers, one for inside and one for outside, a stander, a 
wooden corner chair, two cardboard corner chairs (one used on the playground and one used in the classroom), a computer desk, and an easel. As each piece of adaptive design was added Zivvie became more actively involved with her peers. Each adaptation added to the early learning environment, met Zivvie’s needs, as she showed an interest in the new activities: Adam: ... with the new equipment it allowed her to choose her activities, it allowed her the freedom to move to materials that she wanted to play with, it allowed her to access new materials, it allowed her to function at activities with her peers.

In Zivvie’s story Adam also discusses how the wooden corner chair, the first of the adaptive designs, was important to facilitate Zivvie’s interactions with her peers, joining with her peers at the table during mealtime in parallel and associative play joining her peers to participate in quiet thinking activities such as puzzles and drawing.

Each of the adaptive designs allowed Zivvie to actively participate in the program and reduced the amount of time she was being supported physically by her teachers. Social interactions change when the adult is removed from the play activities (Katz \& Galbraith, 2006; Kim, 2005; Odom, 2002). Kim (2005) states that once the adult was removed from the play, the children approach the child with disabilities. My observational data supports this research. When Zivvie used the Adaptive Design chair, to support her in the sandbox, the children approached her independently; they made eye contact directly with her and they brought toys to her engaging in associative play.

Madeline: The biggest thing about equipment is that it allows [Zivvie] access to the other children and to play with the other children at their level, because the play changes when there is an adult sitting behind holding [Zivvie]. 
Cheryl reflects in her story that the change in adaptive designs allowed Zivvie to participate in activities as an equal to her peers:

She had mobility, she was the same size as the other kids when she was standing up, while petite she certainly was not an infant anymore, and that really changed how her peers looked at her.

Once the children recognized that Zivvie was a preschooler, like themselves, they started to include her into their play and were also observed making accommodations in the play environment to incorporate Zivvie's Adaptive Design creations. This spontaneous inclusion on the part of other children represents the whole early learning community working together to support Zivvie as an equal. Adam also supports the observational data when relating how the children were now including Zivvie in their play:

Now they are including her, one example is where they built a block structure, I think it was a rocket ship and they asked if they could include Zoe's chair so she could come into the vehicle with them, so she could sit up and actually play a game with them in the dramatic scenario, which is them not viewing the child as an infant but viewing the child as an equal.

This revealed how with the Adaptive Design constructions, Zivvie's social interaction with her peers changed from her being excluded to being included. I observed that the type of play between Zivvie and her peers evolved from onlooker play to participatory play. Gurlanick (1999) states, there are three types of connection in social interactions, passive, interactive and friendship. As Zivvie's story was told the participants relayed the progression from onlooker to participatory play. The final form of friendship was also discussed. Both Madeline and Arthur reflect on this as they told Zivvie's story: 
Madeline: I've seen that shift from being excited to be at school and be around the adults, to being excited about school and being around her peers and her peers coming up to me telling me, “you know, [Zivvie’s] my best friend”

Arthur: One of the things I value right now is having one of the kids come up to her, have a little girl say “Zivvie’s my best friend” because Zivvie’s not able to express that to us and to have another little girl think that Zivvie’s her best friend is wonderful.

"The child is my best friend,” articulates best how Zivvie has successfully made friends with her peers. Her parents also discuss how excited Zivvie had become to enter the classroom and move towards her peers. Zivvie was seen making her own choices of where she wanted to go and with whom she wanted to play with.

It is important for children to have the ability to make their own decisions and choices in the activities they want to participate in and in the peers they want to participate with. Autonomy is paramount in a child's development (Chaille \& Britain, 2003). I observed that the Adaptive Design philosophy lead to the creation of objects that allowed Zivvie to make independent choices of where and with whom she wanted to play. Zivvie was able to access all the learning areas in the classroom:

Adam: I've seen her move towards areas of the classroom where children are playing as opposed to other activities where she generally likes to go.

Madeline adds:

And for [Zivvie] you see her, once you put her in her walker she's off and running and wanting to go play with them and we joke because she barely has time to kiss us goodbye because she's off and after her friends, but that's how a three and half year old should be running off with their friends and saying 'see ya mom' 
With Adaptive Design and the development of age-appropriate objects not only was Zivvie actively seeking the activities the children were involved in her peers were also including Zivvie in their social play, independently creating an environment for her to participate with them.

The use of the adaptive design and the accommodations made to the classroom environment not only changed her social interactions with her peers it also promoted her physical and cognitive development as well:

Madeline: We see her muscle tone increasing. We're hoping her lungs are getting better and I think a big part of that is because she is upright, she's moving around so she has the health benefits of being here. In every area, there have been positive gains.

I mean without her equipment her day would be very, very, different. She can't grow or develop without that equipment.

Adam also comments on Zivvie's development in all domains, discussing her increased physical and cognitive development. The accommodations and use of adaptive designs by Zivvie promoted her development in her ELCC program by allowing her to be actively involved in the program. A child-directed program that allowed Zivvie to make choices of the activities she was interested in and the peers she wanted to play with facilitated her development not only her socio-emotional development but also her physical and cognitive development.

Zivvie’s story told from the perspectives of who cared for her and as such cannot be generalized to the general population. Because Adaptive Design is specific to the individual, her environment and needs, and the ELCC is a very specific location with specific expertise and experience, it is not possible to claim that Adaptive Design is appropriate for other children in different context. As well the program that Zivvie attended followed the social inclusion model of making accommodations to the environment to support the child's difference. What is 
important however is to realize that this is one story among many. The Adaptive Design Association (http://adaptivedesign.org) has over a decade of experience creating devices for children, and inclusive early learning environments have been changing children's lives for decades. Reflecting on Zivvie’s story helps us to understand how Adaptive Design and similar accommodations can either exclude or include a child from becoming a member of their early learning community as a result of our attitudes towards children with disabilities. 


\section{Chapter 6: Conclusion and Recommendation}

My goal in conducting this study was to explore how Adaptive Design changed the social interactions between children in an inclusive ELCC. Through the telling of Zivvie's story, from the perspective of those who cared for her, demonstrates that for Zivvie the use of adaptive designs had a significant and potentially life changing impact on her social interactions and engagement in her physical environment. Depending on the adaptations used to support her physical needs, Zivvie was included or excluded by her peers. When the infant/toddler equipment was used to support Zivvie, her peers reacted to her as if she was an infant not a preschooler. However when Zivvie's needs were being supported by age-appropriate objects that reflected Adaptive Design principles, they allowed her to interact with her peers as an equal and be seen by them to be an autonomous equal. The walker Zivvie used provided her with her mobility and reduced the amount of support she required from the teachers. Having her mobility provided Zivvie with her autonomy to move to areas of the classroom where her peers were playing. This was also true of the wooden and cardboard chairs she used in the classroom and outside; they supported Zivvie's physical needs allowing her to participate in activities with her peers. Her peers included her in their play because of the support that Adaptive Design and similar objects gave her and because she was able to participate in all areas of the classroom. Zivvie was able to choose the activities she wanted to participate in and the peers she wanted to play with. These social interactions with her peers allowed her to develop more mature forms of play.

Zivvie's social interactions with her peers impacted the type of play she was participated in evolving from onlooker play to friendship. Guralnick (1999) describes three forms of connectedness in positive social interactions between children with friendship as the final form 
and most advanced form. "Zivvie is my best friend" was a statement from her peer that demonstrates that Zivvie became a full member of her early learning community. Without the commitment of all the stakeholders to actively engage Zivvie in the early learning community her full membership would be in jeopardy and it is questionable as to whether friendships would develop.

Zivvie's story, through a myriad of lenses, reveals that the stakeholders had to work together as a team, sharing similar beliefs regarding inclusion and that all the stakeholders believed that inclusion meant that all children should be able to fully participate in all activities in the classroom; the zero exclusion policy, the shared goal of having Zivvie actively involved in the ELCC program created an environment that allowed the adaptive designs to be implemented in the learning community. This goal required that teachers make accommodations in the classroom environment to support the use of adaptive designs. As Adam discusses, this was not a static action and was adjusted continually to accommodate the needs of all the children in the program. The stakeholders in the early learning community embraced Zivvie’s difference, recognized her abilities and consulted with each other to incorporate accommodations to the environment to meet her needs. This was also true of her typically developing peers who started to make their own accommodations to the environment to include their friend. This was evident when they built a rocket ship from blocks and incorporated one of her adaptive designs so she could participate.

The adaptive designs used by Zivvie continued to evolve as her needs evolved. The incorporation of the computer desk and easel are examples of this. The computer desk and easel were created to meet her physical needs, allowed her to participate in activities that she demonstrated an interest in and where her peers were engaged in play. Zivvie's story also reflects 
on her physical and cognitive development that evolved while she was supported by adaptive designs.

Zivvie's story is a single case study, and as such cannot be generalized to the general population. However, several recommendations can be made from the information gained from her story. One key piece to Zivvie becoming a full member of her early learning program was how important it was for all the stakeholders to work together as a team. Without the cooperation of all the stakeholders to actively involve Zivvie in all areas and activities of her ELCC program the changes to the environment and accommodations using adaptive designs would not have taken place. Having an inclusion policy at the ELCC of zero reject supported the attitudes and beliefs of the stakeholders.

The changes made to environment, such as moving furniture to widen pathways and removing some pieces of furniture, allowed all the children to participate in all learning centres of the classroom. As Adam suggested this was not a static environment it was a thoughtful arrangement that was continually adjusted to meet the needs of all the children. Creating an environment that is fluid can make it accessible for all members of the learning community.

The research regarding the use of Adaptive Design methods and social interactions between children in an ELCC is limited. Zivvie's story reflects on her experience in her classroom. Her story gave us a glimpse into how accommodations can include or exclude a child from their peers and the positive developmental benefits for the child. Each adaptation was specifically created for Zivvie’s use and was required to support her personal needs and her development. The pieces that were built by the ECE students at the EDGE lab, based on the Adaptive Design methods were created in consultation with all the stakeholders in the study and 
were unique to Zivvie’s needs. Continued research into the theory and design process of Adaptive Design is required to support the information presented in this study.

I chose to tell the story of Zivvie, using this narrative inquiry method, to develop a dialogue regarding how adaptive designs changed the social interactions of all the children in an early learning community. It is my hope that Zivvie's story will inform and inspire others so that all children can become an equitable member of their early learning community. 


\section{Appendix A}

\section{Recruitment Letter}

\section{Adaptive Design, Social Inclusion and the Preschool Child: One Child’s Story}

Dear Parents, Teachers and Supervisor;

My name is Alison Gaston. I am a graduate student in the Master of Early Childhood Studies at Ryerson University. As part of the requirements I am doing a Masters Research Project (MRP) study on Adaptive Design, Social Inclusion and the Preschool Child.

The purpose of the study is to determine how the environment and the use of adaptive designs affected the social interactions of a child with special needs with their peers in an inclusive early learning centre. For this study we are recruiting parents with a child who has special needs, teachers and supervisors.

The benefits of participating in this research study is providing data that may be used by early childhood education and educators to develop classroom environments using adaptive designs to foster children's social integration in an inclusive classroom.

If you are interested in participating in this study please contact:

\section{Graduate Student Researcher: Alison Gaston}

Graduate Student, Masters in Early Childhood Studies

Early Childhood Education, Ryerson University

350 Victoria Street, Toronto, ON M5B 2K3

agaston@ryerson.ca

416-979-5000

\section{Supervisor:}

Dr. Jason Nolan, Assistant Professor, Early Childhood Education, Ryerson University

350 Victoria Street, Toronto, ON M5B 2K3 jnolan@ryerson.ca 416-979-5000 ext. 7030

If you have questions regarding your rights as a human subject and participant in this study, you may contact the Ryerson Research Ethics Board for information.

Research Ethics Board

C/o Office of the Vice President, Research and Innovation

Ryerson University

350 Victoria Street

Toronto, ON M5B 2K3, 416 -979-5042 


\section{Appendix B}

Research Subject Information and Consent Agreement (Parent)

Adaptive Design, Social Inclusion and the Preschool Child: One Child’s Story

\section{Dear Parents,}

My name is Alison Gaston. I am a graduate student in the Master of Early Childhood Studies at Ryerson University. As part of the requirements I am doing a Masters Research Project (MRP) study on Adaptive Design, Social Inclusion and the Preschool Child.

The purpose of the study is to determine how the environment and the use of adaptive designs affected the social interactions of a child with special needs with their peers in an inclusive early learning centre. For this study we are recruiting parents with a child who has special needs, teachers and supervisors.

You are being asked to participate in a research study. Before you give your consent to volunteer yourself as a parent for this research study, it is important that you read the following information and ask as many questions as necessary to be sure you understand what you and your child will be asked to do.

You will be asked to participate in an individual interview with the primary investigator. The interview will be conducted with the primary investigator who will ask a series of open-ended questions. The questions asked will be similar to the following: What type of adaptive designs does your child use? How has the use of these designs affected your child in the classroom? Can you discuss the changes you have seen in your child since the introduction of adaptive designs? You will be asked to provide written and oral answers to the questions asked by the primary investigator. The interview will be recorded with audio for review. The data collected and answers to the questions will be analyzed. The interview will take place in a location that is convenient for you and will provide you with privacy.

There may be minimal risks to you as the study may require answers that may be emotionally difficult for you to discuss. If you feel uncomfortable at anytime you may discontinue participation, either temporarily or permanently. Participation in this study is voluntary; you are free to leave the research study at any time. Your child will be free to not participate and may leave the task at anytime. Your choice of whether or not to participate will not influence your future relations with Ryerson University.

The benefits of participating in this research study is providing data that may be used by early childhood education and educators to develop classroom environments using adaptive designs to foster children's social integration in an inclusive classroom.

The data collected will remain completely confidential, neither you, nor your child's name, will be associated with the data collected. 
If you have any questions about the research now, please ask. If you have questions later about the research you may contact:

\author{
Graduate Student Researcher: \\ Alison Gaston \\ Graduate Student, Masters in Early Childhood Studies \\ Early Childhood Education, Ryerson University \\ 350 Victoria Street, Toronto, ON M5B 2K3 \\ agaston@ryerson.ca \\ 416-979-5000
}

Supervisor:

Dr. Jason Nolan, Assistant Professor, Early Childhood Education, Ryerson University 350 Victoria Street, Toronto, ON M5B 2K3 jnolan@ryerson.ca 416-979-5000 ext.7030

If you have questions regarding your rights as a human subject and participant in this study, you may contact the Ryerson Research Ethics Board for information.

Research Ethics Board

C/o Office of the Vice President, Research and Innovation

Ryerson University

350 Victoria Street

Toronto, ON M5B 2K3

$416-979-5042$ 


\section{Research Subject Consent Agreement (Parent):}

Your signature below indicates that you have read the information in this agreement and have had a chance to ask any questions you have about the study. Your signature indicates that you agree to be in the study, you are giving your consent for your child (named below) to participate in this study and you give your consent to allow information regarding your child to be used in this study. You have been told that you can change your mind and withdraw your consent for you and your child to participate at any time. You have been given a copy of this agreement.

You have been told that by signing this consent agreement you are not giving up any of your legal rights.

Name of Parent/ Guardian (please print)

Name of Child (please print)

Signature of Parent/Guardian

Date

Signature of Investigator

Date 


\title{
Appendix C
}

\author{
Research Subject Consent Agreement (Teacher(s) and Supervisor)
}

\begin{abstract}
Adaptive Design, Social Inclusion and the preschool Child: One Child’s Story
\end{abstract}

\section{Dear Teacher(s)/Supervisor,}

My name is Alison Gaston. I am a graduate student in the Master of Early Childhood Studies at Ryerson University. As part of the requirements I am doing a Masters Research Project (MRP) study on Adaptive Design, Social Inclusion and the Preschool Child.

The purpose of the study is to determine how the environment and the use of adaptive designs affected the social interactions of a child with special needs with their peers in an inclusive early learning centre. For this study we are recruiting parents with a child who has special needs, teachers and supervisors.

You are being asked to participate in a research study. Before you give your consent to volunteer yourself as a teacher/supervisor for this research study, it is important that you read the following information and ask as many questions as necessary to be sure you understand what you and your child will be asked to do.

You will be asked to participate in an individual interview with the primary investigator. The interview will be conducted with the primary investigator who will ask a series of open-ended questions. The questions asked will be similar to the following: What type of adaptive designs does the child use? How has the use of these designs affected the child in the classroom? Can you discuss the changes you have seen in the child since the introduction of adaptive designs? You will be asked to provide written and oral answers to the questions asked by the primary investigator. The interview will be recorded with both audio and video for review. The data collected and answers to the questions will be analyzed. The interview will take place in a location that is convenient for you and will provide you with privacy.

There may be minimal risks to you as the study may require answers that may be emotionally difficult for you to discuss. If you feel uncomfortable at anytime you may discontinue participation, either temporarily or permanently. Participation in this study is voluntary; you are free to leave the research study at any time. Your choice of whether or not to participate will not influence your future relations with Ryerson University.

The benefits of participating in this research study is providing data that may be used by early childhood education and educators to develop classroom environments using adaptive designs to foster children's social integration in an inclusive classroom.

The data collected will remain completely confidential your name will not be associated with the data collected. 
If you have any questions about the research now, please ask. If you have questions later about the research you may contact:

\author{
Graduate Student Researcher: \\ Alison Gaston \\ Graduate Student, Masters in Early Childhood Studies \\ Early Childhood Education, Ryerson University \\ 350 Victoria Street, Toronto, ON M5B 2K3 \\ agaston@ryerson.ca \\ 416-979-5000
}

Supervisor:

Dr. Jason Nolan, Assistant Professor, Early Childhood Education, Ryerson University 350 Victoria Street, Toronto, ON M5B 2K3 jnolan@ryerson.ca 416-979-5000 ext.7030

If you have questions regarding your rights as a human subject and participant in this study, you may contact the Ryerson Research Ethics Board for information.

Research Ethics Board

C/o Office of the Vice President, Research and Innovation

Ryerson University

350 Victoria Street

Toronto, ON M5B 2K3

$416-979-5042$ 


\section{Research Subject Consent Agreement (Teacher/Supervisor):}

Your signature below indicates that you have read the information in this agreement and have had a chance to ask any questions you have about the study. Your signature indicates that you agree to participate in the study, and have been told that you can change your mind and withdraw your consent to participate at anytime. You have been given a copy of this agreement.

You have been told that by signing this consent agreement you are not giving up any of your legal rights.

Name of Teacher/ Supervisor (please print)

Signature of Teacher/Supervisor

Date

Signature of Investigator

Date 


\section{Appendix D}

\section{Child's Assent Form}

To receive the child's assent the primary investigator will as the child for their assent using the following protocol:

May I ask your parents, teachers (name of teachers will be used) and supervisor (name of supervisor will be used) questions about you and the adaptive designs you use in the classroom? Researcher received a verbal or physical assent: yes __, no

May I use their answers to my questions in an article? An article is like a story for adults to read? Researcher received a verbal or physical assent: yes__, no 


\section{Appendix E}

Interview Guideline: Adaptive Design, Social Inclusion and the Preschool Child:

One Child’s Story

Can you describe how the adaptive designs used in this inclusive preschool environment affected the child with special needs (use name of child) and their social interactions with their peers?

Additional questions will be generated from the answer 


\section{Resources}

Adaptive Design Association Inc. Retrieved February 28, 2011 from http://www.adaptivedesign.org.

Aguier, C., Moiterio, A.R., \& Pimental, J. (2010). Classroom quality and social acceptance of preschoolers with disabilities. Infants and Young Children, 23(1), 34-41.

Barret, M. (2009). Sounding lives in and through music: A narrative inquiry of the 'everyday' musical engagement of a young child. Journal of Early Childhood Research, $7(2), 115-134$.

Batchelor, D., \& Taylor, H. (2005). Social inclusion the next step: User-friendly strategies to promote social interaction and peer acceptance of children with disabilities. Australian Journal of Early Childhood, 30(4), 10-18.

Best Start Expert Panel on Early Learning (2007). Early learning for every child today: A framework for early childhood settings. Retrieved from http://www.ontla.on.ca/library/repositiory/mon/17000/274085.pdf.

Bloor, M. \& Wood, F. (2006). Keywords in qualitative research: A vocabulary of research concepts. London, Great Britain: Sage Publications.

Boeije, H. (2010). Analysis in qualitative research. London, England: Sage Publications.

Brown, M., \& Bergen, D. (2002). Play and social interaction of children with disabilities at Learning/Activity centers in an inclusive preschool. Journal of Research in Childhood Education, 17(1), 26-37.

Bruner, J. (2002). Life as narrative. Social Research, 71(3), 691-710. 
Bunch, G., Finnegan, K., Humphries, C., Dore, R. \& Dore, L. (2005). Finding a way through the maze: Crucial terms used in education provisions for Canadians with Disabilities. Crucial Terms Final Report, Toronto, ON: The Marsha Forest Centre. Retrieved from http://www.marshaforest.com/crucialterms.pdf.

Chaile, C. \& Britain, L. (2003). The young child as a scientist:A constructivist approach to early childhood science education ( $3^{\text {rd }}$ ed.). New York: Pearson Education, Inc.

Clandinin, D.J. \& Connelly, F.M. (2000). Narrative inquiry: Experience and story in qualitative research. San Francisco, CA: Josey-Bass Inc.

Cresswell, J. W. (2009). Research design: Qualitative, quantitative and mixed methods Approaches. $3^{\text {rd }}$ Edition. Thousand Oaks, CA: Sage Publishers.

DiCarlo, C.F. \& Vagianos, L. (2009). Using child preferences to increase play across the interest centers in inclusive early childhood classrooms. Young Exceptional Children, 12(4), 31-39.

Division of Early Childhood and National Association for the Education of Young Children (2009). Early childhood inclusion: A summary. Young Exceptional Children, 13(1), 52-53.

Dyson, L.L. (2007). The unexpected effects of inclusion on the families of students with learning disabilities: A focus-group study. Learning disabilities: A Multidisiplinary Journal 14(7), 185-194.

Experiential Design and Gaming Lab (2011). Retrieved February 27, 2011, from http://edgelab.ryerson.ca/adaptive-design-studio/.

Frankfort-Nachmias, C. \& Nachmias, D. (2000). Research Methods in the social sciences. $6^{\text {th }}$ Edition, New York, New York: Worth Publishers. 
Garrick Duhaney, L.M. \& Salend, S. J. (2000). Parental Perceptions of Inclusive Education Placements. Remedial and Special Education, 21(2), 121-128.

Gena, A. (2006). The effects of prompting and social reinforcement on establishing social interactions with peers during the inclusion of four children with autism in preschool. International Journal of Psychology, 41(6), 541-554.

Grenier, M. (2010). Moving to inclusion: a socio-cultural analysis of practice. International Journal of Inclusive Education, 14(4), 387-400.

Guralnick, M. (1999). The nature and meaning of social integration for young children with mild developmental delays in inclusive settings. Journal of Early Intervention, 22(1), 70-86.

Guralnick, M. (2001). A framework for change in early childhood inclusion. In M.J. Guralnick (Ed.), Early childhood inclusion: Focus on change (pp.3-35). Baltimore: Brookes.

Guralnick, M. J., Neville, B., Hammond, M. A., \& Connor, R. T. (2007). The friendships of young children with developmental delays: A longitudinal analysis. Journal of Applied Developmental Psychology, 28(1), 64-79.

Harper, L. \& McClusky, K. (2002). Caregiver and peer responses to children with language and motor disabilities in inclusive preschool programs. Early Childhood Research Quarterly, 17(2002), 148-166.

Irwin, S., Lero, D. \& Brophy, K. (2004). Inclusion: the next generation in child care in Canada. Wreck Cove, Nova Scotia: Breton Books.

Janson, U. (2001). Togetherness and diversity in preschool play. International Journal of Early Years Education, 9(2),135-143. 
Janson, U. (2007). Preschool cultures and the inclusion of children with disabilities. The Japanese Journal of Special Education, 44(6), 405-422.

Katz, L. \& Galbraith, J. (2006). Making the social visible within inclusive classrooms. Journal of Research in Childhood Education, 21(1), 5-21.

Kim, S. D. G. (2005). Kevin: "I gotta get to the market": The development of peer relationship inclusive early childhood settings. Early Childhood Education Journal, 33(3), 163-169.

Leyser, Y. \& Kirk, R. (2004). Evaluating inclusion: an examination of parent view and factors Influencing their perspectives. International Journal of Disability, Development and Education, 51(3), 271-285.

Meyer, L.H. (2001). The impact of inclusion on children's lives: Multiple outcomes and friendship in particular. International Journal of Disability, Development and Education, 48(1), 9-31.

Neuman, W. L. (2006). Social research methods: Qualitative and quantitative approaches (6 $6^{\text {th }}$ ed.). Boston: Allyn \&Bacon/Pearson.

Odom, S. L. (2000). Preschool inclusion: What we know and where we go from here. Topics in Early Childhood Special Education, 20(1), 220-227.

Odom, S. L. (2002). Narrowing the question: Social integration and characteristics of children with disabilities in inclusion settings. Early Childhood Research Quarterly, 17(2), 167-170.

Odom, S. L. \& Bailey, D. B. (2001). Inclusive preschool programs: Ecology and child outcomes. In M.J. Guralnick (Ed.), Early childhood inclusion: Focus on change (pp.253-276). Baltimore: Brookes. 
Odom, S. L., Brown, W. H., Schwartz, I. S., Zercher, C., \& Sandall, S. R. (2002). Classroom ecology and child participation. In S. L. Odom, P. J. Beckman, M. J. Hanson, E. Horn, J. Leiber, S. R. Sandall, I. S. Schwartz, \& R. A. Wolery (Eds.), Widening the circle:Including children with disabilities in preschool programs (pp. 25-45). New York: Teachers College Press.

Odom, S. L., Zercher, C., Li, S., Marquart, J. M., Sandall, S., \& Brown, W. H. (2006). Social acceptance and rejection of preschool children with disabilities: A mixed-method analysis. Journal of Educational Psychology, 98(4), 807-823.

Palmer, D.S., Fuller K., Arora, T. \& Nelson, M. (2001). Taking sides: Parent views on Inclusion for their children with severe disabilities. Exceptional Children 67(4), 467-484.

Smith, B. \& Sparkes, A.C. (2008). Narrative and it's potential contribution to disability studies. Disability and Society, 23(1), 17-28.

Stahmer, A. C., Carter, C., Baker, M. \& Miwa, K. (2003). Parent’s perspective on their toddlers’ development: Comparison of regular and inclusion childcare. Early Childhood Development and Care, 173(5), 477-488.

Stanton-Chapman, T. L., Jamison, K. R., \& Denning, C. B. (2008). Building school communication skills in young children with disabilities: An intervention to promote peer social interactions in preschool settings. Early Childhood Services: An Interdisciplinary Journal of Effectiveness, 2(4), 225-251.

Tomascoff, C. (2009). Among the Giants [Documentary]. Retrieved February 28, 2011 from http://vimeo.com/8264094. 
Vessel, N., Engelbrecht, P., Oswald, M. M., Eloff, I. \& Swart, E. (2007). Views of Inclusion a comparative study of parent's perceptions in South Africa and the United States. Remedial and Special Education, 28(6), 356-365.

Vygotsky, L. S. (1978). In Cole M. (Ed.), Mind in society: The development of higher psychological processes. Cambridge, Mass.: Harvard University Press.

Webster, L. \& Mertova, P. (2007). Using Narrative Inquiry as a research method: an introduction to using critical event narrative analysis in research on teaching and learn London: Routledge. 